\title{
TO COMPARE THE PREVALENCE OF SEXUAL DYSFUNCTIONS AMONG MOOD AND PSYCHOTIC DISORDERS: A CROSS-SECTIONAL STUDY
}

\author{
Bhuvana C. Revappala1, Jaya Bharathi², Revathi K. Gowda ${ }^{3}$ \\ ${ }^{1}$ Consultant Psychiatrist, Wellspring Mind Care, Sharavathinagara, Shimoga. \\ 2Psychologist, Wellspring Mind Care, Sharavathinagara, Shimoga. \\ ${ }^{3}$ Assistant Doctor, Wellspring Mind Care, Sharavathinagara, Shimoga.
}

\begin{abstract}
BACKGROUND

Sexual dysfunction is the common symptoms in psychiatric illness like mood and psychotic disorders, which may be related to the psychopathology which can complicate the treatment if ignored by the clinicians. Most of the earlier studies were done based on the effects of psychotropic medications on sexual functions. However, it is not clear to what extent the psychiatric disorders itse lf are responsible for the sexual impairment.

Aim is to compare the prevalence of sexual dysfunction among the patients presenting with psychotic and mood disorders before starting psychotropic medications.
\end{abstract}

\section{MATERIALS AND METHODS}

Out of total 60 numbers of patients, each of the 30 members belonged to mood and psychotic disorders groups, aged between 18 to 45 years of either sex were included. Sexual dysfunctions are assessed by using SHF (Sexual History Form). Chi-square test has been used to compare the prevalence in both groups and p-value of $<0.05$ is considered significant statistically.

\section{RESULTS}

The overall prevalence of sexual dysfunctions were found to be more in mood disorder (63.3\%) group than psychotic disorder group (50\%), but does not find any significance statistically. Severity of illness associated with sexual dysfunction is found to be more in mood disorder groups than psychotic disorder group with statistically significant $(\mathrm{p}<0.05)$.

\section{CONCLUSION}

Sexual dysfunctions are found to be common in both psychotic and mood disorders, suggesting it is intrinsic to the development of illness before starting psychotropic medications. Sexual dysfunctions which affects in more than one domain of sexual functions are usually associated with the psychotic symptoms in both groups. This suggests that they are mediated by the same underlying neurobiological factors.

\section{KEYWORDS}

Sexual Dysfunctions, Mood Disorders, Psychotic Disorders.

HOW TO CITE THIS ARTICLE: Revappala BC, Bharathi J, Gowda RK. To compare the prevalence of sexual dysfunctions among mood and psychotic disorders: a cross-sectional study. J. Evolution Med. Dent. Sci. 2016;5(83):6202-6207, DOI: 10.14260/jemds/2016/1401

\section{BACKGROUND}

Sexual dysfunction is one of the most important psychological disorders in psychiatric clinic and in general population. Despite increasing demand for clinical services and potential impact of these disorders on interpersonal relationship and quality of life, epidemiological data are relatively scant. 1,2 If the physician fails to recognise of having SD that are usually associated with psychiatric disorders or vice-versa, it complicates the treatment and worsens the prognosis of one another. Based on the few available community studies it appears that SD are highly prevalent in both sexes, ranging from $10 \%-52 \%$ in men and $25 \%-63 \%$ in women. $3,4,5$

Adequate sexual expression is one of the most important components in maintaining a satisfying intimate relationship, which also provides a sense of physical, psychological and

Financial or Other, Competing Interest: None.

Submission 21-09-2016, Peer Review 09-10-2016,

Acceptance 11-10-2016, Published 17-10-2016.

Corresponding Author:

Dr. Bhuvana C. Revappala,

Wellspring Mind Care,

Sharavathinagara, Shimoga.

E-mail: doc.barbie@yahoo.in

DOI: $10.14260 /$ jemds $/ 2016 / 1401$

(c) (i) $\$$ social well-being and may enhance the quality of life. Sexual dysfunction is the difficulty experienced by an individual or a couple during any stage of a normal sexual activity like physical pleasure, desire, arousal and orgasm.6.7 According to the DSM-5 to diagnose a person is having the sexual dysfunction requires a person to feel extreme distress and interpersonal strain for a minimum of 6 months (Excluding substance or medication-induced sexual dysfunction) duration and can have a profound impact on an individual's perceived quality of sexual life. ${ }^{8}$

The prevalence estimation of sexual dysfunction depends on many factors. First the method of enquiry; for example, the incidence of sexual dysfunction may have ranged between $10 \%-14 \%$ when relying on spontaneous reporting, but it ranged between $38 \%-65 \%$ when patients were questioned directly by clinicians. Second, spouse's expectations about the sexual performance of their partner and the degree of willingness to discuss these problems can vary widely between different cultures.

Third, the terms used to define sexual dysfunction are based upon the subjective beliefs and perceptions of what is normal sexual functioning. Finally, increased awareness of sexual matters and availability of medical treatments for having these problems from the sources like media, health 
magazines, internet, etc., leads the young trends to perceive themselves as suffering from sexual dysfunction than compared to adult population results in bias in prevalence estimations. ${ }^{9,10}$

Sexual problems are highly prevalent among the patients with psychiatric disorders like mood and psychotic disorders. They may be caused by the psychopathology of the psychiatric disorder or sexual dysfunction itself may progress to the psychiatric disorder and can worsen one another. In spite of this it is generally underestimated, often neglected and poorly managed by the clinicians.

The current International Classification of Mental and Behaviour disorders (ICD-10) has identified two categories of mood disorders: The depressive disorders and the bipolar disorders. Each of these disorders can have a significant impact on a person's sexual wellbeing. ${ }^{11}$

Depression a mood disorder, is characterised by the loss of interest, reduction in energy, lack of self-esteem, inability to experience pleasure, irritability and social withdrawal. These depressive symptoms can lead to decreased frequency of sexual contact, decreased sexual pleasure and satisfaction, which later worsens the sexual dysfunction. This constellation of symptoms may be expected to produce difficulties in maintaining sexual relationship. The prospective Zurich cohort study shows that the prevalence of sexual problems in depressed subjects (Including those with major depression, dysthymia and recurrent brief depression) is approximately twice that in controls (50\% versus $24 \%$ ). But these studies were done based on those who were on antidepressant medications and hence actual prevalence estimation of sexual dysfunction in depressed patients is not known.12,13,14

Bipolar disorder, also called manic depressive disorder, is another mood disorder. Their moods can swing, go from one extreme to the other and then back again, i.e. high levels of euphoria in one extreme and depressive episode in other extreme. Life events, medication or recreational drug use can trigger mania or depression. Both moods can last anywhere from a few days to a few months. It can also affect sexuality and sexual activity. They may have periods of hypersexuality during manic episode and then lose interest in sex during depressive episode. 15 Hypersexuality means having an increased interest in sex and more frequent sexual urge. These people may find unable to achieve sexual satisfaction despite a lot of sexual activities where clinician may bias and moreover these people may have out of control for sex drive have multiple sex partners including strangers, excessive masturbation, inappropriate and risky sexual behaviour. These people may experience the opposite of hypersexuality during a depressive episode. Hyposexuality often creates relationship problems, because partner does not understand their partner's current sex drive issues. These are especially true during the extreme mania with hypersexual behaviour and then suddenly experience depression and lose interest in sex and their partner may feel confused, frustrated and rejected. A recent study (Dell'Osso et al, 2009) showed the sexual dysfunction was significantly more common in patients with mood disorders (Bipolar I Disorder and Unipolar Depression) compared with control subjects, but rate not mentioned. $16,17,18,19$

Sexual dysfunction is also common in people with psychotic disorders like schizophrenia and other psychotic disorders. It is known to affect all the areas of sexual function; likes, desire, arousal, erection, ejaculation and orgasm..$^{1,2}$ It is generally unexplored or ignored by clinicians or attracted only vague reassurances resulting in poor medication adherence and quality of life. Another study (Pinderhughes et al, 1972) has showed that professionals believed people with schizophrenia were unable to manage their sexuality and that staffs were reluctant to discuss sexual issues with them. So far sexual dysfunction has been largely attributed only to the deleterious effect of antipsychotic medications ${ }^{20,21}$ with reported prevalence rates of $30 \%-80 \%$ in women and 45 $80 \%$ in men, ${ }^{1-6}$ where the recent data has suggested that it may be a consequence of the disease itself and it would be evident in people with prodromal symptoms before the full development of frank illness of psychosis before the start with antipsychotic medication. ${ }^{12,13}$

To test this hypothesis, we assessed the prevalence of sexual dysfunction among the individuals with psychotic and mood disorders before starting psychotropic drugs, as there is a nil/negligible study in India.

\section{MATERIALS AND METHODS \\ Sample}

Samples were collected from patients visiting psychiatric clinic in Shimoga city. Samples have been divided into two groups: psychosis group includes prodromal symptoms of psychosis; those who already developed psychosis who is cooperative for interview and mood disorders group which includes depressive disorders, manic and bipolar disorders. Each group consists of 30 patients and none of the both groups had received psychotropic treatment during the assessment. Informed consent has been taken from each patient before starting study.

\section{Assessments}

All the patients who visited the psychiatric clinic were diagnosed based on ICD-1011 diagnostic criteria and categorised as psychotic disorders and mood disorders. We also screened the young people who are at risk, whom having family history of psychosis by using the Comprehensive Assessment of At-Risk Mental States (CAARMS) 22 to assess the prodromal symptoms of psychosis. To be included in the study participants needed to meet the CAARMS criteria with the highest score to consider it as a prodromal phase of psychosis. ${ }^{16}$ Sexual dysfunction has been assessed by using SHF and FSFI. Severity of psychiatric illness was assessed by using the rating scales like PANSS, HAM-D and YMRS.

\section{Instruments Used}

CAARMS - Comprehensive Assessment of At Risk Mental States. CAARMS is a scale used to determine if an individual meets the criteria for ultra high risk of psychosis and prodromal symptoms of psychosis. CAARMS demonstrates adequate validity and inter-rater reliability and appears to be helpful in the prediction of psychosis transition. In this study we only included the prodromal symptoms of psychosis, due to difficulty of follow-up of the ultra high risk of psychosis cases to assess the psychosis transition state after 2 years duration. ${ }^{22}$

\section{SHF}

The Sexual History Form. ${ }^{13}$ The SHF is a self-reporting measures consisting of 46 multiple-choice items that have variable numbers of response options (e.g., Item 1 has 9 
options; Item 18 has 6 options). Reliability ranged from .92 (Creti et al, 1988) to .98 (Libman et al, 1989). Internal consistency ranged from .50 to .70 . It is validated and specifically constructed to assess the sexual functioning in patients with mental illness like psychotic and mood disorders. But this scale validity is more in men than women. ${ }^{23}$

\section{PANSS}

Positive and Negative Syndrome Scale.

PANSS is a scale used for measuring symptom severity patients with schizophrenia and psychosis (Stanley Kay, Lewis Opler and Abraham Fiszbein; 1987). It helps to assess both positive symptoms consisting of 7 items, negative symptoms consisting of 7 items and general psychopathology consists of 16 items. The interviewer must be trained to a standardised level of reliability. 24

\section{HAM-D}

Hamilton's depression rating scale. HAM-D scale is used to assess severities of depressive disorders. ${ }^{25}$

\section{YMRS}

Young's Mania Rating scale. ${ }^{12}$ It used to assess severities of bipolar disorders. ${ }^{26}$

\section{ICD-10}

International classification of Mental and Behaviour disorders, Psychotic disorders includes - Schizophrenia (F.20),

Persistent delusional disorders (F.22), Psychosis NOS (F.28); Mood disorders include - Manic and Hypomanic episodes (F30), Bipolar affective disorders (F-31), Depressive disorders with or without psychotic symptoms (F-32), Recurrent depressive disorders (F-33). ${ }^{11}$

\section{Statistics}

The Chi-Square test was used to compare two groups, $\mathrm{p}$-value $<0.05$ was considered significant statistically and data were analysed by using SPSS version 19.0.

\section{Inclusion Criteria}

- $\quad$ Age group b/w 18-45 years of either sex.

- No past history of antidepressant and antipsychotic medications.

- $\quad$ BPAD and RDD with no past history of psychotropic medications.

- Both married and unmarried.

\section{Exclusion Criteria}

- $\quad$ Age $>45$ years and $<18$ years.

- Acute and transient psychotic disorder.

- RDD who were on antidepressant medications.

- Substance abuse.

- Bipolar disorders not included due to having treatment history.

- Organic psychosis.

- Medical or physiological cause of sexual dysfunction (Hypothyroidism, diabetes mellitus or other endocrine or metabolic disorder, vascular disorders and neurological disorders), history of head trauma or injury, history of serious surgical illness or intellectual disability.

\section{RESULTS}

The data collected is summarized in the form of tables and respective histograms as depicted below. Table 1 reports the overall prevalence of sexual dysfunctions in both groups, which were found to be more in mood disorders group (53.3\%) than psychotic disorder group (46.6\%), but does not find any significance statistically. In patients with mood disorders, loss of sexual libido/desire found to be more common $(40 \%)$ than psychotic disorder $(20 \%)$, but is not found significant, whereas premature ejaculation is more common in psychotic disorder group and were found significant statistically $(\mathrm{p}<0.05)$. The prevalence of erectile dysfunction and orgasmic dysfunction were found to be equal in both groups (6.7\%).

\begin{tabular}{|c|c|c|c|}
\hline $\begin{array}{l}\text { Chi- } \\
\text { Square } \\
\text { Test }\end{array}$ & $\begin{array}{c}\text { Sexual } \\
\text { Dysfunctions }\end{array}$ & $\begin{array}{c}\text { Psychotic } \\
\text { Disorders } \\
\text { n (\%) }\end{array}$ & $\begin{array}{c}\text { Mood } \\
\text { Disorders } \\
\text { n (\%) } \\
\end{array}$ \\
\hline $\mathrm{X} 2=0.27$ & $\begin{array}{c}\text { Hypoactive } \\
\text { sexual disorder } \\
\text { (desire/arousal) }\end{array}$ & $6(20 \%)$ & $12(40 \%)$ \\
\hline $\mathrm{df}=1$ & $\begin{array}{c}\text { Erectile } \\
\text { dysfunction }\end{array}$ & $2(6.7 \%)$ & $2(6.7 \%)$ \\
\hline \multirow[t]{4}{*}{$P=0.606$} & $\begin{array}{c}\text { Orgasm } \\
\text { dysfunction }\end{array}$ & $2(6.7 \%)$ & $2(6.7 \%)$ \\
\hline & $\begin{array}{c}\text { Sexual pain } \\
\text { disorders }\end{array}$ & $1(3.3 \%)$ & $3(10 \%)$ \\
\hline & $\begin{array}{l}\text { Premature } \\
\text { ejaculation }\end{array}$ & $4(13.3 \%)$ & $0(0 \%)$ \\
\hline & Total & $\begin{array}{c}15 \\
(50.0 \%)\end{array}$ & $\begin{array}{c}19 \\
(63.3 \%)\end{array}$ \\
\hline \multicolumn{4}{|c|}{$\begin{array}{c}\text { Table 1: Prevalence of Sexual Dysfunction } \\
\text { Types b/w Two Groups }\end{array}$} \\
\hline
\end{tabular}

\section{Graph 1}

Shows that the results of a linear regression analysis testing the hypothesis of relation $b / w$ Positive and Negative Syndrome Scale (PANSS) and Sexual History Form scores. Diagonal line is fit line for total. There is a positive association between symptoms severity and SHF scores $\left(r^{2}=0.955, y=\right.$ $16 \mathrm{x}+0.6)$.

\section{Graph 2}

Shows that the results of a linear regression analysis test the hypothesis of relation b/w Hamilton Depression rating scale (HAM-D) and Sexual History Form (SHF) scores. Diagonal line is fit line for total. There is a positive association between symptoms severity and SHF scores $\left(\mathrm{r}^{2}=0.814, \mathrm{y}=\right.$ $0.78 x+17.21$ ) for HAM-D than YMRS score. Since both groups have found linear regression $r^{2}$ value appropriately to be 1.0, it indicates that knowing $X$ lets us predict $Y$ perfectly and hence it is found significant. Greater symptoms severity of psychiatric illness showed sexual dysfunction in more than one domains as compared to mild severity of illness. YMRS scale does not show any linear regression due to their hypersexuality and reports decreased satisfaction. 


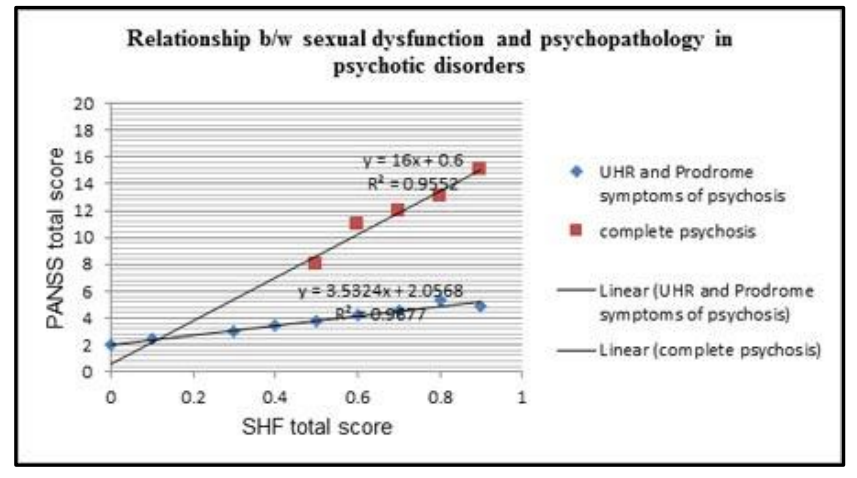

Graph 1

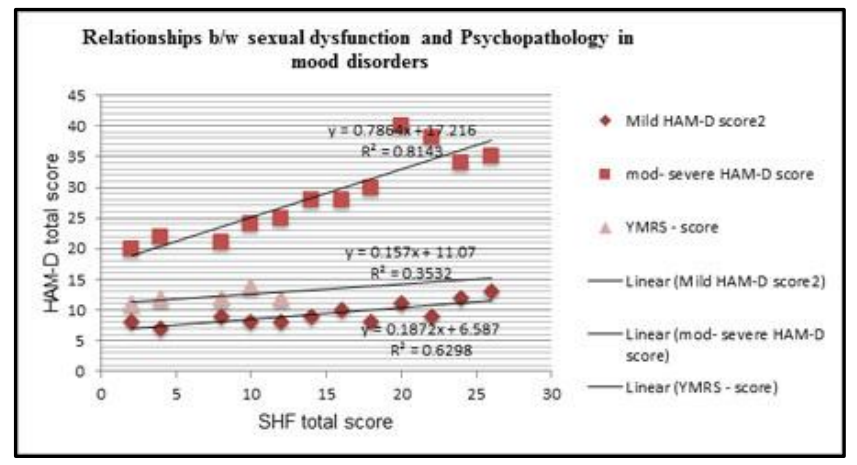

Graph 2

\begin{tabular}{|c|c|c|c|}
\hline \multicolumn{2}{|l|}{ Psychotic Group } & \multicolumn{2}{|c|}{ Mood Disorder Group } \\
\hline Gender & n (\%) & n (\%) & \\
\hline Male & $07(23.0 \%)$ & $05(16.7 \%)$ & $\mathrm{X}^{2}=3.270$ \\
\hline Female & $07(23.0 \%)$ & $11(36.3 \%)$ & $\mathrm{df}=1, \mathrm{P}=.071$ \\
\hline Age, years in mean (Both sexes)(s.d.) & $34.50(6.118)$ & $31.97(7.020)$ & $\mathrm{t}=1.490, \mathrm{df}=58, \mathrm{P}=0.142$ \\
\hline Associated Factors (Headache) & $7(46.6 \%)$ & $12(63.15 \%)$ & \\
\hline
\end{tabular}

Table 2 reports the demographic measures for each group and headache was found to be as associated factors in both groups, but reasons not known.

Graph 3, Chi-Square Tests $\mathrm{X}^{2}=10.80, \mathrm{Df}=1, \mathrm{P}=0.001$

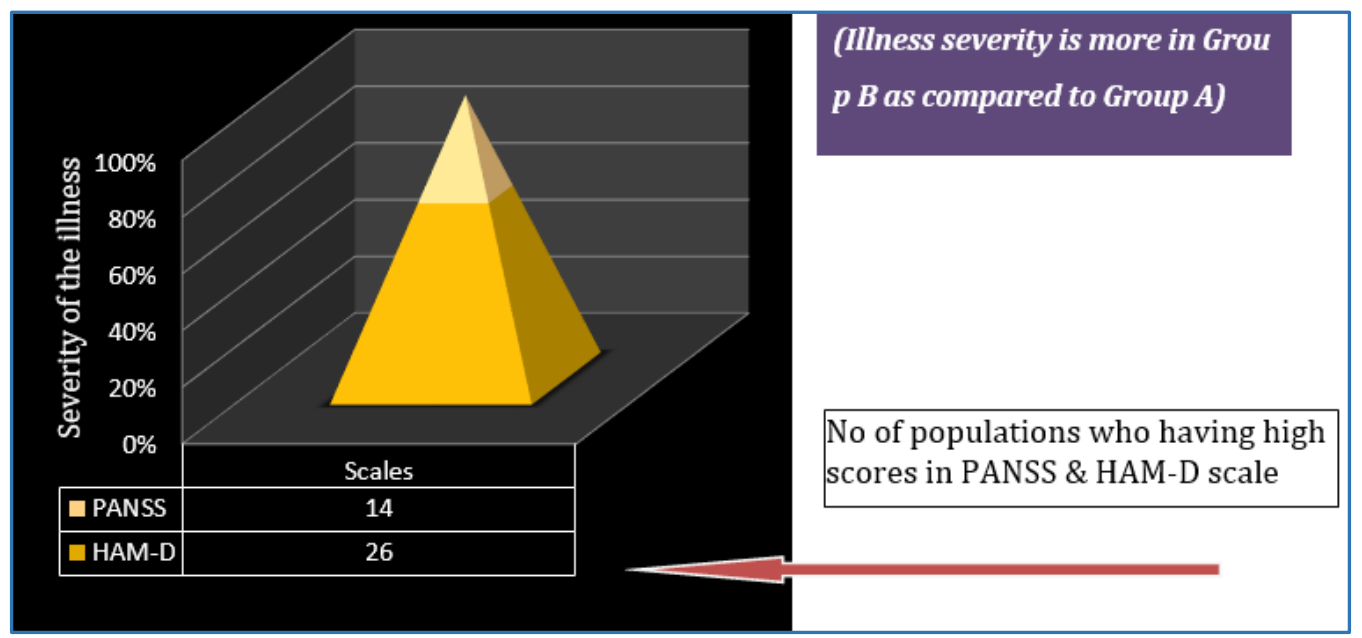

Graph 3

Graph 3 showing that number of population having severity of psychiatric illness in both groups. Severity of illness associated with sexual dysfunction is found to be more in mood disorder groups than in psychotic groups with significant statistically ( $\mathrm{p}<0.05$ ). A positive relationship between the severity of the illness and sexual dysfunction has been found where it affects more than 1 domains of sexual function.

\begin{tabular}{|l|l|}
\hline \multicolumn{1}{|c|}{ Psychotic Disorder Group } & \multicolumn{1}{c|}{ Mood Disorder Group } \\
\hline Schizophrenia-8 & Depression with psychotic symptoms -12 \\
\hline Persistent delusional disorders-6 & Mod-severe depression-4 \\
\hline Psychosis NOS-4 & Mild depressive episode-4 \\
\hline Prodromal symptoms of psychosis-12 & RDD-1 \\
\hline \multirow{2}{*}{} & Hypomania-2 \\
\cline { 2 - 2 } & Mania-1 \\
\cline { 2 - 2 } & Bipolar disorder current episode mania-1 \\
\cline { 2 - 2 } & Dysthymia-5 \\
\hline \multicolumn{2}{|c|}{ Table 3: Number of Psychiatric Disorders in Both Groups } \\
\hline
\end{tabular}

\section{DISCUSSION}

To our knowledge this is the first study in India to compare the prevalence of sexual dysfunction among the individuals presenting with Psychotic (50\%) and Mood disorders (63.3\%) before starting psychotropic medications, but the results does not show any significant differences between the two groups. Our study had showed that sexual function is impaired prior to the onset of the illness of first psychotic episode, i.e. sexual 
dysfunction can begin during the prodromal stage of psychotic disorders. Furthermore, greater symptom severity in both groups was associated with greater impairment in sexual function, i.e. it affects more than one domains of sexual functions. We did not find an effect of age and gender in the severity of sexual dysfunction in both the groups. Our analysis had showed that there is a positive linear relationship between symptom severity (PANSS/HAM-D/YMRS) and total SHF score in both the groups before taking any psychotropic medications.

Moreover in patients with bipolar disorders, especially among manic/hypomanic episode due to their hypersexuality in nature reports of having sexual dysfunction. According to case reports, some patients suffering from psychotic symptoms experience coenesthetic hallucinations (i.e. the sensation of bodily functions that are usually undetectable) of a sexual nature, erotomanic delusions, delusions related to sexual identity, the sexual act or pregnancy. Both of above symptoms may result in study bias.

Nonetheless, patients and clinicians does not easily start to discuss sexual functioning. Most patients when asked are willingly and relieved to discuss sexual problems. Studies suggest that talking about sexuality does not destabilise patients. Even those with treatment-resistant schizophrenia may wish to talk about these topics. In contrast, clinicians often do not ask and underestimate the rates of sexual dysfunctions as well as their negative impact on their lives. Some clinicians may not know enough about the issue or feel ashamed of talking about these sensitive subjects. ${ }^{20,21}$

The pathophysiology behind the development of sexual dysfunctions among the psychotic disorders remain unclear. They can be secondary to the disease itself, negative symptoms or an adverse event of antipsychotic medication. To test this hypothesis, so far only one study (Tiago Reis Marques 2012) has compared the prevalence of sexual dysfunction in individuals at Ultra-High Risk group (UHR) of psychosis, first episode of psychosis and a healthy control group. They have found that Sexual dysfunction was evident in $50 \%$ of the UHR group, $65 \%$ in first-episode of psychotic patients and $21 \%$ in healthy controls. His study findings is showing for the first time that sexual dysfunction were already present in individuals at ultra-high risk of psychosis, even prior to full onset of psychotic disorders and also even before starting antipsychotic medication, which are consistent to our study findings. [4,21]

Our study data indicates that although depressive disorders contribute to sexual dysfunction, most of the people had sexual dysfunction during severity of depressive illness, as they do not fully explain all the areas of sexual dysfunctions as seen in people with a psychotic disorder. ${ }^{27,28}$

This suggests that components of sexual dysfunctions are linked to the psychotic symptoms and this indicates the degree to which sexual dysfunction was related to severity of depression as compared to mild severity. This suggests that they are mediated by the same underlying neurobiological factors. One potential candidate is dopaminergic dysfunction, which is already present at the ultra-high-risk stage/prodromal stage, but appears to progress with the onset of psychotic disorders and disrupt the arousal pathways required for sexual function. ${ }^{20,21}$
The Zurich study provides comparative data on the prevalence of sexual problems in untreated depressed patients and depressed patients receiving either medications antidepressants or psychotherapy. Sexual problems were more prevalent in depressed patients who received treatment (62\%) than who did not (45\%) and both groups had a higher prevalence of sexual dysfunction than controls (26\%). However, there were no statistically significant differences in the prevalence of any type of sexual dysfunction between the patients treated with medication $(62 \%)$ or psychotherapy alone $(63 \%))^{29,30,31}$

In bipolar disorders, Dopamine dysregulation is responsible for mood cycling. The dopamine hypothesis states that the increase in dopamine level results in secondary homeostatic downregulation by increase in the dopamine mediated G protein-coupled receptors. This results in decreased dopamine transmission, which leads to the depressive phase of the bipolar disorders. ${ }^{18,19}$ This depressive phase ends with homeostatic upregulation potentially restarting the cycle over again leads to manic phase.[16] Due to dysregulation of dopamine, which affects the tuberoinfundibular tract can lead to both amenorrhea and sexual dysfunctions which are associated with elevated prolactin levels induced by low DA transmission. ${ }^{17}$

Recent work (John M. Grohol, Psy.D. 2009) has done on stress factor, which plays a key role in the pathogenesis of sexual dysfunction and psychiatric disorders. Other study (Aksoy et al 2013) indicates that psychiatric disorders can often accompany headaches like TTH, migraine, cluster and other headaches which are sensitive to stress factors, results in the pathogenesis of SD. Consistent to the above opinion, our study also found the headache as an associated factor in both mood disorders (63.15\%) and psychotic disorders (46.6\%).32 This result suggests psychiatric disorder alone cannot explain the sexual dysfunction as headache also a plays role.

\section{CONCLUSION}

Sexual dysfunction associated with both psychotic and mood disorders before starting psychotropic medications suggesting that it is intrinsic to the development of illness. Sexual dysfunctions which affects in more than one domain of sexual functions are usually associated with the psychotic symptoms in both groups. This suggests that they are mediated by the same underlying neurobiological factors. Furthermore, greater symptom severity in this group was associated with greater impairment in sexual function, i.e. it affects more than one domains of sexual functions. The potential causes of sexual dysfunction in patients with mood and psychotic disorders are complex and little investigated and future research must explore the various biological/psychological/psychosocial factors that are likely to be the causes of sexual dysfunctions.

\section{Implications}

First, psychiatrists do not routinely enquire about the sexual dysfunction which are usually associated with mood and psychotic disorders which can complicate the treatment of each other, hence psychiatrists need to enquire routinely in this area.

Second, the reasons for not asking about sexual dysfunction routinely include lack of confidence of healthcare professionals in asking these questions, lack of confidence in 
available treatment, risk of upsetting vulnerable people and time constraints.

Finally, our study proved that sexual dysfunction is usually associated with psychiatric illness before starting medications and found sexual dysfunctions. So treatments for sexual dysfunction needs to be considered seriously as both are interrelated as causing factors, if we ignore it will worsen the symptoms of other.

\section{LIMITATIONS}

First, we did not assess physiological/medical causes of sexual dysfunctions. Although several studies have reported associations between these factors, our study focused on the sexual functioning in a non-medicated group in whom we expected prolactin levels to be normal.

Second, the size of the bipolar affective disorders disorder was small and most were hypomania during interview. Our study is limited by the small sample size. We were not able to interview mania with psychotic disorders. Further investigations are required on larger samples in order to better clarify particular aspects of sexual dysfunctions in BD patients.

Finally, we were not able to interview the patients among those who were having full frank psychosis and mania with psychotic disorders, which may result in study bias.

\section{REFERENCES}

1. Morokoff PJ, Gilliland R. Stress, sexual functioning, and $m$ arital satisfaction. J Sex Res 1993;30(1):43-53.

2. Fugl-Meyer AR, Lodnert G, Branholm IB, et al. On life satis faction in male erectile dysfunction. Int J Impot Res 1997; 9(3):141-8.

3. Frank E, Anderson C, Rubinstein D. Frequency of sexual d ysfunction in normal couples. N Engl J Med 1978;299(3): 111-5.

4. Rosen RC, Taylor JF, Leiblum SR, et al. Prevalence of sexu al dysfunction in women: results of a survey study of 329 women in an outpatient gynecological clinic. J Sex Marital Ther 1993;19(3):171-88.

5. Spector IP, Carey MP. Incidence and prevalence of the sex ual dysfunctions: a critical review of the empirical literat ure. Arch Sex Behav 1990;19(4):389-408.

6. Nolen-Hoeksema S. Abnormal psychology. $6^{\text {th }}$ edn. New Y ork: McGraw-Hill 2014:366-7.

7. Eden KJ, Wylie KR. Quality of sexual life and menopause. Women's Health (Lond) 2009;5(4):385-96.

8. Jeste DV, Lieberman JA, Fassler TD, et al. Diagnostic and s tatistical manual of mental disorders, DSM-5. $5^{\text {th }}$ edn. USA : American Psychiatric Association 2013:423-59.

9. Rosen RC. Prevalence and risk factors of sexual dysfuncti on in men and women. Curr Psychiatry Rep 2000;2(3):18 9-95.

10. Laumann EO, Paik A, Rosen RC. Sexual dysfunction in the United States: prevalence and predictors. JAMA 1999;281 (6):537-44.

11. World Health Organization. International classification of mental and behavioural disorders, ICD-10. 10 th edn. 1992 :234-238.

12. Baldwin D, Mayer A. Sexual side-effects of antidepressant and antipsychotic drugs. Advances in Psychiatric Treatm ent 2003;9(3):202-10.

13. Marques TR, Smith S, Bonaccorso S, et al. Sexual dysfunct ion in people with prodromal or first-episode psychosis. Br J Psychiatry 2012;201:131-6.
14. Kennedy SH, Dickens SE, Eisfeld BS, et al. Sexual dysfunct ion before antidepressant therapy in major depression. J Affect Disord 1999;56(2-3):201-8.

15. Mazza M, Harnic D, Catalano V, et al. Sexual behavior in $w$ omen with bipolar disorder. Journal of Affective Disorder s 2011;131(1-3):364-7.

16. Shabani A, Ahmadzad MA, Zangeneh K, et al. Quality of lif e in patients with bipolar disorder: is it related it disorde r outcome? Acta Medica Iranica 2013;51(6):386-93.

17. Grover S, Ghosh A, Sarkar S, et al. Sexual dysfunction in cl inically stable patients with bipolar disorder receiving lit hium. J Clin Psychopharmacol 2014;34(4):475-82.

18. Berk M, Dodd S, Kauer-Sant'anna M, et al. Dopamine dysr egulation syndrome: implications for a dopamine hypoth esis of bipolar disorder. Acta Psychiatr Scanda 2007;116( Suppl 434):41-9.

19. van Rossum I, Tenback D, van Os J. Bipolar disorder and d opamine dysfunction: an indirect approach focusing on ta rdive movement syndromes in a naturalistic setting. BMC Psychiatry 2009;9:16.

20. Nagaraj AK, Nizamie HS, Akhtar S, et al. A comparative st udy of sexual dysfunction due to typical and atypical anti psychotics in remitted bipolar-I disorder. Indian J Psychi atry 2004;46(3):261-6.

21. Macdonald S, Halliday J, MacEWAN T, et al. Nithsdale schi zophrenia surveys 24: sexual dysfunction. Case-control st udy. Br J Psychiatry 2003;182:50-6.

22. Yung AR, Yuen HP, McGorry PD, et al. Mapping the onset o f psychosis: the comprehensive assessment of at-risk me ntal states. Aust N Z J Psychiatry 2005;39(11-12):964-71.

23. Fichten L, Llibman CSE, Kalogeropoulos D, et al. A global s core for the sexual history form and its effectiveness. Pre sentation at the 21st annual convention of the Associatio $\mathrm{n}$ for Advancement of Behavior Therapy, Boston, Mass 19 87.

24. Kay SR, Fiszbein A, Opler LA. The positive and negative sy ndrome scale (PANSS) for schizophrenia. Schizophr Bull 1987;13(2):261-76.

25. Hamilton M. A rating scale for depression. J Neurol Neuro surg Psychiatry 1960;23:56-62.

26. Young RC, Biggs JT, Ziegler VE, et al. A rating scale for ma nia: reliability, validity and sensitivity. Br J Psychiatry 19 78;133(5):429-35.

27. Nicolosi A, Moreira ED, Villa M, et al. A population study o $\mathrm{f}$ the association between sexual function, sexual satisfact ion and depressive symptoms in men. J Affect Disord 200 4;82(2):235-43.

28. Montejo-González AL, Liorca G, Izquierdo JA, et al. SSRI-in duced sexual dysfunction: fluoxetine, paroxetine, sertrali ne and fluvoxamine in a prospective, multicenter, and de scriptive clinical study of 344 patients. J Sex Marital Ther 1997;23(3):176-94.

29. Bhugra D, De Silva P. Sexual dysfunction across cultures. I nt Rev Psychiatry 1993;5(2-3):243-52.

30. Baldwin DS. Depression and sexual function. J Psychopha rmacol 1996;10(Suppl 1):S30-4.

31. Angst J. Sexual problems in healthy and depressed perso ns. Int Clin Psychopharmacol 1998;13(Suppl 6):S1-4.

32. Grohol JM. Biological basis for stress-induced sexual dysf unction. Psych Central 2009. 